\title{
PEDAGOGIAS ATORIAIS: \\ ESTRATÉGIAS DE COLABORAÇÃO, CONCEPÇÃO E COMPOSIÇÃO NA FORMAÇÃO DE ATORES
}

\section{Actor's pedagogies:}

strategies of collaboration, conception and composition in the actors' teaching

\author{
Alice Stefânia Curi \\ Universidade de Brasília - UnB
}

Resumo: O texto apresenta e discute proposta pedagógica cujos princípios adotados visam à investigação e corporificação da noção de dramaturgia de ator e à construção coletiva de um corpus comum de saberes e fazeres ligado ao texto ou contexto eleito para o exercício de montagem.

Palavras-chave: Dramaturgia de ator; Pedagogia de ator; Colaboração.

Abstract: The text presents and discusses the pedagogical path in which principles adopted aim at searching and embodying an actor's dramaturgic notion and the collective construction of a common corpus of savoir-faire linked to the chosen staging text.

Keywords: Actor's dramaturgy; Actor's pedagogy; Collaboration. 
Vivemos um tempo em que se identifica importante alienação dos sentidos do corpo, ainda que possa, paradoxalmente, parecer um tempo de liberdade e fluidez. Diferentes pensadores denunciam mecanismos sutis, mas importantes de extorsão de nossa potência de ser. Trata-se de processos a que somos sujeitados pela apropriação perversa de nossos desejos, que são empurrados a um consumo automatizado e acrítico, e pela cooptação de nossa libido enquanto força produtiva em uma lógica de mercado. Como diz Amílcar de Barros:

O corpo, uma vez coisificado e estratificado, é apto para estabelecer sua aderência material e imaterial no sistema produtivo, ou seja, a inserção da corporeidade e da corporeidade como linguagem e capital de (re)produção e consumo. (BARROS, 2011, p. 80) ${ }^{1}$

Diante disso, que corpo é este que chega às escolas de formação de atores? Como este corpo cria neste contexto? Como romper com certo silenciamento corporal e proporcionar encontros com a corporeidade que favoreçam criação, autoconhecimento, autoexpressão e maior problematização crítica diante do mundo? Cada pessoa, cada estudante, e em especial o de artes cênicas, precisa ser apoiado a reencontrar ou reinventar, através da corporeidade, sua própria relação com o mundo, com estratégias de desautomatização da percepção e de fomento à habilidade de proposição reflexiva e poética. Esse processo passa necessariamente por experimentar a própria corporeidade de modos diversos.

\footnotetext{
1 A tradução do espanhol para o português de todos os trechos da obra de Barros é nossa.
}

O corpo é uma construção social, cultural e ideológica, como também o são o olhar, a palavra, seu nomeamento, sua validação, sua configuração e sua (de)codificação; só são possíveis a partir de e num trajeto que ocorre na corporeidade. (BARROS, 2011, p. 80)

É preciso que haja espaços que autorizem experiências sensíveis e fomentem a construção de um olhar poético e questionador sobre o mundo. O questionamento nasce do espanto, gesto de estranhamento, como bem sabia Brecht, desnaturalização do que é dado como estável ou imutável. O espanto dificilmente acontece se estamos anestesiados em nosso cotidiano. Estratégias para estados de presença, para imergir na experiência concreta de estar-no-mundo, podem se mostrar, assim, potencialmente disparadoras de eventos micropolíticos de transformação. Como diz Hans Ulrich Gumbrecht:
Se compreendermos o nosso desejo de presença como uma reação a um ambiente cotidiano que se tornou tão predominantemente cartesiano ao longo dos últimos séculos, faz sentido esperar que a experiência estética possa nos ajudar a recuperar a dimensão espacial e a dimensão corpórea da nossa existência; faz sentido esperar que a experiência estética nos devolva pelo menos a sensação de estarmos-no- mundo, no sentido de fazermos parte de um mundo físico de coisas. (GUMBRECHT, 2010, p. 146)

Provocada por inquietações como estas e confrontada ao cotidiano de sala de trabalho com atores em formação, fui desenvolvendo uma perspectiva metodológica, a ser abordada nesse texto. A disciplina Interpretação e Montagem integra o currículo vigente do Bacharelado em Interpretação Teatral, do Departamento de Artes Cênicas da 
Universidade de Brasília (UnB), ocorrendo no quinto semestre letivo, dentre os sete que compõem o fluxo do curso. Desde meu ingresso como professora nesta instituição, em 2009, até o presente momento, ministrei essa disciplina em diferentes oportunidades.

Desenvolvi a abordagem à disciplina tendo em vista que os estudantes a cursam após a consolidação de uma base pedagógica ligada a princípios da linguagem cênica no que concerne a corpo, voz, interpretação, teoria e história do teatro, dramaturgia e elementos de encenação, e ainda considerando que a mesma antecede o Projeto de Diplomação, onde se espera que os estudantes apresentem maior autonomia e verticalidade de pesquisa. A ementa da disciplina sinaliza:

Discurso e pesquisa: consolidação das diferentes experiências desenvolvidas ao longo do curso, no contexto de uma montagem cênica, experimentando conceitos e fundamentos de técnicas de interpretação sistematizados a partir da segunda metade do século $\mathrm{XX}^{2}$.

Os princípios pedagógicos adotados no contexto desta disciplina visam tanto ao exercício de produção e composição expressiva por parte dos corpos cênicos quanto à construção coletiva de um corpus comum de saberes e fazeres articulados direta ou transversalmente ao texto eleito para montagem. Ambas as abordagens operam como uma orientação poética e concepcional para criação colaborativa.

Jorge Dubatti, no contexto de uma Filosofia do

\footnotetext{
2 Projeto Político Pedagógico do curso de Interpretação Teatral, da Universidade de Brasília.
}

Teatro, se refere a "três ângulos de análise da poética: trabalho, estrutura e concepção" (2016, p. 61). Em relação à noção de trabalho, a observação se concentra sobre "o trabalho humano durante o acontecimento teatral" envolvendo artistas, técnicos e espectadores, o "trabalho nos processos anteriores ao acontecimento", como ensaios, montagens, etc., "o trabalho entre os acontecimentos (de um espetáculo a outro) e posteriores ao acontecimento" (2106, p. 61). Neste artigo, abordarei particularmente $o$ trabalho atorial nos processos anteriores ao acontecimento. Em relação à estrutura, segunda noção do tripé, o autor a apresenta articulada à noção de organicidade:
A ideia de organicidade implica ao mesmo tempo a de uma nova unidade material-formal ontologicamente específica e a de uma organização interna singular dos componentes, hierárquica, por seleção e combinação, por meio de procedimentos relevantes, mas em grau diverso. A estrutura é o resultado da nova forma que opera sobre as matérias informadas. (DUBATTI, 2016, p. 61)

A perspectiva apresentada pelo autor convoca noções facilmente relacionáveis à ideia de composição, também estruturante deste estudo, tais como: seleção, organização interna, combinação, unidade material-formal. Já sobre a dimensão concepcional, terceiro eixo do tripé sugerido por ele, Dubatti diz:

Chamo de concepção de teatro a forma como, prática (implícita) ou teoricamente (explícita), o teatro concebe a si mesmo e concebe suas relações com o conjunto do que há no mundo: o ser humano, a sociedade, o sagrado, a linguagem, a 
política, a ciência, a educação, o sexo, a economia, etc.". (2016, p. 62)

Visando proporcionar um trabalho pautado nas dimensões composicional e concepcional da obra cênica, optei por abordar o programa da disciplina em quatro etapas. Ao longo de todas elas, visa-se ao exercício e apropriação de princípios técnicos de preparação de ator, através da repetição de uma série de exercícios que definimos nos primeiros encontros, dentre alguns propostos por mim e outros pelos próprios estudantes. Em geral, construímos um pequeno treino de cerca de trinta minutos, constituído por atividades psicofísicas interligadas em um fluxo corporal contínuo e orgânico. São posturas e exercícios de Yoga e/ou Chi Kung, exercícios de alongamento e força ligados ao Pilates e outras fontes, conjugados à respiração, práticas vocais e canções. Em geral, finalizamos a série inicial com uma roda como uma ciranda ou congênere, ou com alguma prática aeróbica, lúdica e/ou de coordenação motora - como pular corda ou jogos com bastão, ou ainda com alguma dinâmica voltada ao despertar da atenção e prontidão.

O trabalho técnico e poético pode ser amparado por práticas meditativas e/ou de investigação e regulação vibrátil da corporeidade, ligadas à Yoga, ao Chi Kung e outras fontes, abrindo ou fechando essa série inicial. Compreende-se que tais procedimentos podem favorecer uma abertura maior ao devir do trabalho, à instauração de um campo experiencial, ainda que o contexto de sala de aula torne a proposta mais desafiadora. Como diz Gumbrecht:
Uma tal eventividade é certamente diferente de uma situação de aula, em que procuramos facilitar o acontecimento do aparecimento estético, embora estejamos completamente cientes de que nenhum esforço pedagógico garantirá a vinda da experiência concreta. Mas podemos apontar a presença de determinados objetos de experiência e convidar os alunos à serenidade, isto é, a estarem ao mesmo tempo concentrados e disponíveis, sem deixarem que a concentração calcifique na tensão de um esforço. (2010, p. 132)

Na primeira etapa da disciplina, que detalharei a seguir, proponho ainda, após esta série inicial, laboratórios de investigação corporal e de princípios técnicos do trabalho de ator, como mapeamento e graduação de impulsos e intratensões, modos de instauração de presença e estados, construção e desconstrução de gestos e ações, composições corpóreas individuais e coletivas, treinos de coralidade, etc. Parte dessa experiência já promove a emergência dos primeiros materiais corporais expressivos que os estudantes vão selecionando e registrando na forma de uma partitura corporal que configura uma espécie de acervo poético de cada corpo cênico.

\section{Etapa 1: das pedras}

\author{
um solo para trilhar \\ habitar encruzilhadas \\ pedras soltas no caminho \\ presença de natureza instável
}

Nesta etapa, com duração de cerca de três semanas, propõe-se uma série de práticas exploratórias que visam uma imersão em contextos de experiência corporal e energética, estimulando-se a porosidade e atravessamentos poéticos. Além disso, 
abordamos algum aprimoramento técnico e já focamos em levantamento de um acervo expressivo corpóreo-vocal. Este acervo tratase de um conjunto de matrizes, ações, gestos, vocalidades, estados, etc., selecionados nos laboratórios vividos, que são apropriados, organizados e trabalhados no contexto de partituras individuais. Tal material expressivo não guarda necessariamente relação inicial com o texto eleito para a encenação. Materiais de cada partitura podem posteriormente ser partilhados com outros atores, a depender das demandas do processo. Paralelamente instauram-se rodas de leituras e diálogos, até chegarmos à escolha de um texto para a montagem.

O levantamento de material poético por parte dos atores sem associação direta com a obra a ser trabalhada fomenta uma investigação corporal não teleológica, não objetivada e não ilustrativa. Com esse conjunto de práticas, visa-se o exercício de produção de presença e descoberta de sentidos para além de lógicas predominantemente semânticas, figurativas ou de ênfase hermenêutica. Na medida em que miramos em uma obra cênica que não seja mimética ou redundante ao texto, buscamos um caminho de escovar o 'sentido à contrapelo', 'trair' para 'extrair' outros sentidos. Concordamos com Gumbrecht que:

A relação entre efeitos de presença e efeitos de sentido também não é uma relação de complementaridade, na qual uma função atribuída a cada uma das partes em relação à outra daria à copresença das duas a estabilidade de um padrão estrutural. Ao contrário, podemos dizer que a tensão/oscilação entre efeitos de presença e efeitos de sentido dota 0 objeto de experiência estética de um componente provocador de instabilidade e desassossego. (2010, p. 137)

Esta fase do trabalho visa ao exercício de apetências e aptidões que compreendo dentro do escopo da noção de dramaturgias de ator, noção que discuto em artigo anterior:

Nessa perspectiva, a corporeidade configura-se (...) como um motor relacional, uma usina de onde se irradiam forças, tensões, vetores de enunciação. Estão em jogo fricções do corpo consigo mesmo, com outros corpos e com toda a materialidade cênica. Mais que conflitos à moda psicológica, são turbulências, fissuras, fraturas, atritos. A noção de dramaturgia de ator articula-se a essa potência de produção e desestabilização do signo a partir de ações do corpo em cena. Dramaturgias atoriais tensionam a enunciação semântica a uma constelação de latências: sentidos que emergem de experiências sensoriais, associativas, mnemônicas, emotivas, vibráteis. (CURI, 2013, p. 934)

A formação corporal de estudantes durante o ensino médio muitas vezes se estrutura prioritariamente sobre princípios do esporte e da funcionalidade física, o que pode colaborar imensamente na conquista de algumas habilidades motoras, mas não contempla necessariamente uma imersão na complexidade das potências corporais. Como pontua Amílcar de Barros, "abstrairse da corporalidade nos procedimentos de ensino-aprendizagem é reduzir, encapsular e abstrair o perceptivo, o sinestésico, o experiencial e sua intensidade estética da dimensão epistêmica" (2011, p. 81). Neste sentindo, concordo que a abordagem pedagógica em disciplinas dos cursos de artes cênicas tem o mister de, além de

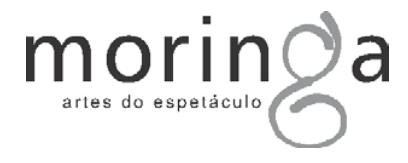


fomentar o aprimoramento técnico, também subverter e redimensionar as perspectivas puramente funcionais da experiência corporal.

\section{É fundamental questionar a formação corporal para além das habilidades físicas, ou técnicas específicas de produção, mímeses e rendimento. Para pensar o corpo do ator (...) é necessário estabelecer e entender o corpo como um lugar praticado e não resolvido (resuelto no original), ou seja, como um campo de possibilidades, um buraco negro ou um abismo de forças e afecções contínuas. (BARROS, 2011, p. 65)}

Após este período de imersão na própria corporeidade, e após decisão coletiva a respeito do texto ou mote da encenação, procedemos à criação de um cronograma de intervenções de pesquisa por parte de grupos de estudantes. Essa agenda configura o principal eixo da segunda etapa da disciplina.

\section{Etapa 2: dos ventos}

torvelinho de respirações arejando ideias a-ventando hipóteses in-ventando escolhas

Dedicamos cerca de um mês a um processo de pesquisa e alimentação colaborativa da rede poética e concepcional comum. À medida que todos se engajam no levantamento de informações, referências, transversalidades e inspirações, e, posteriormente, à medida que se decide coletivamente pelos eixos norteadores da obra, fomenta-se um ethos de grupo, um sentimento de pertencimento e de responsabilização em relação ao processo.

Ao longo dessa etapa há a realização de duas naturezas de intervenções propostas por grupos de estudantes. O primeiro tipo de intervenção voltada para pesquisa é uma espécie de seminário seguido de debate, ou outro formato de aproximação teórica que o grupo queira propor. Aqui, os grupos são incentivados a provocar desde um olhar sobre a obra à moda de uma análise dramatúrgica, ou trazer uma pesquisa sobre o universo do autor e contexto de sua produção, ou ainda propor o estudo de outras questões, direta ou transversalmente ligadas ao (con)texto escolhido.

O segundo modo de intervenção por parte dos grupos se configura como uma provocação prática voltada ao levantamento de material poético e expressivo do coletivo. Os estudos do ciclo anterior podem indicar aspectos ou materiais a serem explorados nesse momento. É possível orientar práticas que se voltem à corporeidade, e ainda ao trabalho do corpo cênico na fricção com investigações cenográficas, de figurinos, de objetos, musicalidades, sonoridades, visualidades, propostas híbridas, etc.

Penso que essa etapa da disciplina - que inclui uma dimensão imersiva e exploratória em âmbito teórico e outra dimensão de experimentação, atualização e corporificação de provocações, e que se fundamenta em provocações criadas e organizadas pelos próprios estudantes a partir de debates coletivos - cria aberturas para o campo da complexidade, dialogando com o que defende Gumbrecht nessa passagem:

Se o confronto com a complexidade (...) é o que torna específico o ensino acadêmico, então - em vez de obsessivamente atribuirmos sentido e, por essa via, oferecermos soluções deveríamos, o mais possível, procurar 
uma prática de ensino na modalidade da experiência vivida. (2010, p. 158)

Entendo que a diversidade e o frescor de visões, inspirações e provocações que surgem nesta perspectiva não seriam tão férteis se as propostas estivessem mais concentradas em uma só figura, no caso a da professora. É, ainda, um modo dos estudantes revisitarem, atualizarem e consolidarem experiências pregressas (advindas do curso ou de outras vivências fora do contexto acadêmico), contaminadas por suas próprias percepções e intuições de jovens atores em processo de amadurecimento, e articuladas a diferentes aspectos do texto eleito e vetores transversais apontados.

Os grupos podem permanecer os mesmos nas duas intervenções, ou pode haver migrações ou novas configurações a depender das circunstâncias. Faz parte do trabalho dos grupos, ao longo das duas intervenções, realizar registros, propor uma coleta de materiais, fomentar discussão e indicar diretrizes para pré-seleção das questões trazidas e dos materiais poéticos (corporais e outros) gerados, visando nutrir o acervo concepcional-criativo comum à turma e ainda os acervos de cada corpo cênico, registrados e exercitados na forma de partituras corporais.

Nesta etapa, estimula-se que aspectos transversais e abordagens interdisciplinares sejam investigados e colocados em trabalho. $O$ texto eleito pode orientar, mas não deve restringir as escolhas. A pesquisa se espraia tanto para questões derivadas do texto quanto para outros apontamentos que se façam relevantes aos desejos de discussão e experiência de cada coletivo. Noto que esta abordagem pedagógica estimula uma maior complexidade nas pesquisas, maior consistência e implicação nas argumentações dos envolvidos, maior abertura para insights e ainda fortalece laços de respeito, cumplicidade, criação e colaboração entre os estudantes e a professora. Voltando a Gumbrecht, este lembra que:
Regressar à visão de Humboldt da sociabilidade específica das instituições acadêmicas ("entusiasmo produzido pela livre interação entre alunos e professores") e ao conceito de "pensamento de risco" pode nos ajudar a afinar os nossos argumentos a favor da verdadeira presença na sala de aula. É que pôr em cena o pensamento de risco (isto é, conduzir nossos alunos "às portas da complexidade, sem atravessar com eles essas portas" nas palavras do classista alemão Karl Reinhardt) não deveria limitar-se a deixar alunos e professores num estado de espanto silencioso. Deveria haver (...) reações diferentes aos diferentes encontros dos alunos com a complexidade, e se a complexidade inicial que eles encontram não está ainda domada, interpretada ou reduzida, essas reações terão o estatuto de (mini)eventos, pois serão de fato imprevisíveis - e, portanto, decisivas para continuar a desenvolver a interação de professor e alunos. (2010, p. 162)

Este engajamento efetivo e afetivo por parte da turma, no que concerne à investigação e construção colaborativa do horizonte poético e concepcional da obra vindoura, de modo não exclusivamente tributário ao texto dramático, fomenta e articula-se à processual compreensão e apropriação de apetências e aptidões ligadas ao campo da dramaturgia do corpo cênico. Como diz Barros: 
Os procedimentos de formação corporal do ator deveriam abordar e sustentar relações transversais e interdisciplinares que permitam emergir a corporeidade como potência de ação rizomática para desterritorializar a tradição epigonal da ação dramatúrgica como centro de poder e enraizamento. Para tanto é fundamental (re)conhecer na tradição dramatúrgica e em sua homologação como relato cênico a tendência semântica de enraizamento e (re)adequação da corporeidade cênica e suas potências de ações e afecções rizomáticas. (2011, p. 91)

Em diálogos posteriores às intervenções, fazemos um primeiro balanço do que surgiu e elegemos diretrizes, princípios, parâmetros, inspirações: a rede poética e concepcional que irá nortear as próximas etapas. Sinto que ao longo desta etapa e das posteriores a turma experimenta uma imbricação efetiva entre aspectos práticos e teóricos. Essas dimensões usualmente polarizadas encontram um espaço-tempo onde se constroem e desconstroem mutuamente em ondas de corporificação e abstração, poetização e reflexão, atualização e virtualização, composição e concepção.

Fechando esta etapa há ainda a divisão de núcleos responsáveis por elementos da encenação: cenografia, figurino, maquiagem, iluminação, música/sonoplastia, produção e outras tarefas que eventualmente se façam necessárias. Os grupos se formam por aptidões e apetências em relação às atribuições dos núcleos criados.

\section{Etapa 3: dos fogos}

incendiar a rede faíscas, combustão, ignição experimentar a alquimia na corporificação
Esta etapa, de cerca de um mês e meio a dois, é voltada ao levantamento da peça, propriamente. Inicialmente, há proposições de esboços de cenas por parte dos estudantes, divididos por recortes do texto ou núcleos de personagens, e ancorados na rede concepcional e poética comum. Os atores buscam ainda, em suas próprias partituras e nas de colegas, materiais que possam apoiar sua construção de personagens, ações, cenas, em uma perspectiva composicional. Eles são estimulados a explorar, escavar e esgarçar seus materiais em termos de graduações e variações rítmicas, de intensidade, decupagem em células menores, diferentes 'preenchimentos' (intenções, subpartituras, estados), etc..

Autonomia é palavra-chave neste momento. A primeira proposta de cena é sempre dos atores-estudantes. Exercitando um lugar de autoria, o ator se coloca mais próximo de um lugar concepcional, político e epistêmico. Dubatti convoca a figura de um ator filósofo, que ele define como "um ator que se interroga e interroga o mundo a partir de suas práticas e saberes" (2016, p. 180). Discutindo as singularidades dessa figura ele remonta à noção de "dramaturgia de ator", à qual se refere como "uma escritura com o corpo, no espaço e no tempo do acontecimento" (2016, p. 177), e sobre a qual compreende que "essa escritura implica também uma leitura: a do próprio ator sobre os materiais dramáticos que ele produz. Um pensamento sobre a própria escritura. O ator escreve e lê sua própria escritura" (2016, p. 177). Esse é o ator que desejamos despertar.

As propostas iniciais de cena são mostradas à turma e instaura-se um processo de lapidação das cenas com apoio da professora e de 
outros colegas. Aqui, a professora assume a função de direção dentro de um processo colaborativo: questiona, provoca, sugere, orienta e, quando necessário, toma decisões, amparada por colaborações do coletivo.

O fluxo dos ensaios sempre abre novas perspectivas e, muitas vezes, redimensiona alguns princípios levantados no início do percurso. Compreendo que, de certo modo, os devires do processo são soberanos. Nesse sentido, se orientações prévias não se mostram potentes, consistentes ou instigantes não há motivos para não rever escolhas ou não experimentar novas aberturas. Gumbrecht fala em uma espécie de "dádiva pedagógica", que se relaciona a essa abertura:

É sobretudo a dádiva de permanecer alerta e absolutamente aberto aos outros, sem cair na armadilha de ficar absorvido por instituições e posições; é a dádiva do bom gosto que se mantém precisamente concentrado nos tópicos que não permitem soluções rápidas e fáceis. Tal abertura e tal cobncentração definem o professor como catalisador de evento. (2010, p. 162)

Por outro lado, de modo mais ou menos explícito, aquilo que nutre um processo desde suas primeiras incursões e imersões acaba se infiltrando de algum modo. Mesmo o que se descarta, em alguma medida se entranha à obra e aos corpos como vestígios, rastros, traços, memórias; como um conjunto de camadas mais ou menos profundas, mais ou menos evidentes, numa espécie de arqueologia da cena. Por vezes, são estratos invisíveis, latentes, que operam (con)substancializando o trabalho e se agenciando com outros estratos, sentidos ou afetos mais patentes.
Paralelamente, nesta etapa, são desenvolvidos os trabalhos de concepção e execução dos grupos de encenação. Como já mencionado, este processo também se desenvolve a partir da orientação concepcional e poética comum e de novas demandas, contornos e devires que vão surgindo ao longo dos ensaios. $\mathrm{Na}$ concepção e execução de cenografia, figurino, sonoplastia e luz, procuramos discutir os partidos tomados em termos de fios dramatúrgicos que se tramam às dramaturgias de ator e de texto para construir a tessitura espetacular.

\section{Etapa 4: das águas}

para um leito de rio águas que o preenchem esculpem, infiltram, transbordam em mergulhos de fluxo e organicidade

Nesta etapa de cerca de uma a duas semanas, espera-se que já exista um primeiro desenho da partitura global do exercício cênico ou espetáculo. É o momento dos ensaios gerais, das lapidações mais sutis e detalhadas, do trabalho ganhar fluxo próprio, apropriação. Para os atores estudantes, o exercício da repetição, de ensaiar a obra toda, é crucial para ganhar organicidade no fluxo de ações.

A esta altura, espera-se que os elementos da encenação já possam ser colocados em jogo com os atores. Proporcionar as interações destes diferentes fios dramatúrgicos em âmbito de ensaio significa um espaço de pesquisa extremamente instigante e disparador de novos sentidos. No contexto dos chamados elementos de encenação, remeto à discussão aberta por Carlos Praude (2015) que, a partir de categorias discursivas da 
Teoria Ator Rede (TAR), de Bruno Latour, originária dos estudos sociais, reflete 0 potencial actante da materialidade nas artes da cena. Pensando sobre as diferentes, simultâneas e articuladas dramaturgias da cena, observa-se a pertinência de adotar-se a noção de actante, compreendido como tudo aquilo que gera e sofre ações, produzindo movimento e diferença.

Nesta rede actancial, mais que o olhar voltado a um inventário de unidades, como elementos estanques, ou a uma fusão homogeneizante $e$ monossêmica dessas unidades, importa perceber, como aponta Praude (2015), os trânsitos entre os movimentos de conectividade, os graus de diferenciação decorrentes desses agenciamentos. Assim, cada actante (ator, iluminador e luz, cenógrafo e cenografia, objetos, visualidades, sonoridades, etc.) operaria potencialmente como um tradutor ou transcriador de conceitos, textos, imagens (rede concepcional e poética), materializando-os em inscrições poéticas na cena, segundo suas próprias características e lógica operacional interna. Tais poéticas quando inscritas no campo da cena reassumem seu papel de actante nos agenciamentos, fricções e associações com outras inscrições-actantes. Em tempo real, os encontros, atritos, simultaneidades e fissuras entre actantes produzem a teia dramatúrgica.

Em lugar da noção de tradução, trabalhada pela TAR e retomada por Praude (2015), tomo emprestada a ideia de transcriação de Haroldo de Campos, pois de algum modo ela coloca em jogo uma tradução mais estética do que semântica, colocando em tensão a noção de fidelidade no campo da tradução poética, assumindo 0 movimento de diferenciação neste processo. Parece-me que, no universo da cena contemporânea, a relação da obra cênica e suas materialidades com um (con)texto de referência tende a deslocar-se de uma perspectiva de tradução enquanto fidelidade para a de transcriação.

A concepção actancial da materialidade cênica apresenta aberturas pedagógicas interessantes. Para o estudante ator, há a possibilidade de friccionar sua produção expressiva com estes actantes não humanos e com isso experimentar desdobramentos insuspeitados de seus materiais corporais. Por outro lado, o fato dos integrantes dos núcleos de criação em elementos de encenação serem atores em formação também favorece a concepção actancial destes elementos.

Sempre que possível, faz-se ensaios abertos nesta etapa, com momentos de troca de impressões com os convidados. As diferentes leituras e percepções que se coleta também nutre o processo de 'fechamento' da obra. Esta etapa conclui com a estreia e mostra do trabalho.

Nesta etapa, ocorre também o fechamento do processo de avaliação dos estudantes. A perspectiva que move o processo avaliativo passa de modo importante pela observação de como se deram as interações e retroalimentações entre aspectos teóricos, técnicos e poéticos por parte de cada estudante. Também levo em consideração o processual desempenho do estudante, ou seja, a percepção de como cada um se mostra no início e no fim do percurso.

Neste sentido, observo, por exemplo, o progressivo desempenho do estudante nas dinâmicas de aprofundamento técnico. Este fator é avaliado tanto a partir do grau de apropriação da série de treinamento, como do grau de aproveitamento e investigação de

Revista Moringa - Artes do Espetáculo, João Pessoa, UFPB, v. 9 n. 1, jan/jun 2018, p. 11 a 22

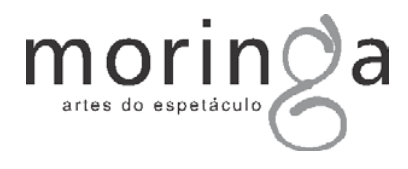


materiais da partitura individual (acervo expressivo de cada um). O que tento perceber e avaliar é como aconteceu para cada estudante a compreensão e o exercício da dramaturgia de ator. Observo ainda como o trabalho de cada ator interage com nossa rede concepcional comum, levando em conta a capacidade de apropriação e ressignificação de material expressivo coletado e o grau de autonomia composicional.

Outro ponto de avaliação são trabalhos escritos entregues, que usualmente preveem o uso de ao menos três referências da bibliografia da disciplina. Dentre os formatos de trabalho já adotados estão: memorial analítico do processo; conjunto de citações comentadas de textos indicados e suas relações com o processo; planos de intervenção experiencial acompanhado de embasamento teórico e metodológico e de discussão de resultados. Aqui, tento identificar o grau de articulação teórico-prática que os estudantes alcançam. Desde o início da disciplina, enfatizo que cada leitura, conceito, categoria ou discussão serão úteis na medida em que apoiarem, inspirarem ou favorecerem análises e críticas sobre os campos da práxis, em suas perspectivas técnica, laboratorial e poética.

Também é objeto de avaliação o desempenho de cada estudante em seus grupos de trabalho ao longo do processo: na intervenção à moda de seminário (discussões, análises, referências); na intervenção experiencial (provocação para levantamento de materiais expressivos); no grupo de encenação. Com essa atividade, tento contribuir na percepção acerca da dimensão pedagógica que 0 trabalho criativo em teatro pode convocar, mesmo quando ocorre fora do espaço da sala de aula. Os procedimentos adotados são eficazes fomentadores de um processo de pesquisa cênica. Na avaliação, tento identificar o grau de compreensão e assimilação desta perspectiva por parte dos estudantes.

\section{Considerações finais}

A força da arte e da educação em arte reside no poder de mobilização no corpo (daquele que produz arte e daquele que frui arte), daquilo que nele é constantemente cooptado e neutralizado. Assim, coloco-me ao lado daqueles que defendem que os campos de arte e de educação em arte sejam exercidos como meios de resistência a processos escamoteados, mas significativos, de automatização e colonização subjetiva. Ressalto a importância de pensarmos estratégias pedagógicas que criem experiências ao mesmo tempo éticas e estéticas. Para que os artistas proponham espaços de deslocamento, é preciso eles mesmos experimentem tais espaços.

Exercícios de alteridade - que são indissociáveis de ações em parcerias, trocas e colaborações, e são vividos intensamente em tarefas a serem cumpridas em pequenos grupos - também se mostram como potentes disparadores de reorganização simbólica e política de regimes coletivos. Processos de criação em artes da cena são espaços privilegiados para tais encontros. Neste sentido, parece-me fundamental que as pedagogias em artes da cena proporcionem tais experiências.

Finalizo sublinhando o potencial políticopedagógico de vivências desta natureza, aliado a seu potencial estético. A construção 
colaborativa de uma base concepcional e poética opera como um importante alicerce para a instauração de processos criativos, favorecendo a composição de obras consistentes e singulares, promovendo engajamento e desenvolvimento crítico dos estudantes, e configurando ainda uma importante sustentação para a gradativa autonomia composicional no contexto da dramaturgia de ator.

Recebido em: 24/01/2018

Aceito em: 09/03/2018

\section{Referências Bibliográficas}

BARROS, Amílcar Borges de. Dramaturgia Corporal. Acercamiento y distanciamento hacia la accion y la escenificación corporal. Santiago: Edtorial Cuarto Propio, 2011.

CURI, Alice Stefânia. Dramaturgias de Ator: puxando fios de uma trama espessa. In: Revista Brasileira de Estudos da Presença. Rio Grande do Sul, UFRGS, volume 3, número 3, pp: 923 - 938, set/dez 2013.

DUBATTI, Jorge. O Teatro dos Mortos. Introdução a uma filosofia do teatro. São Paulo: edições SESC, 2016.

GUMBRECHT, Hans Ulrich. Produção de Presença. $O$ que o sentido não consegue transmitir. RJ: Contraponto e PUC-Rio, 2010.

PRAUDE, Carlos. Arte Computacional e Teoria Ator-Rede: actantes e associações intersubjetivas em cena. Brasília, Programa de Pós-Graduação em Arte/Universidade de Brasília, 2015. Tese em Arte. 